\section{Reflections from an interior world}

\author{
Stephen Jay Gould
}

Memoir of a Thinking Radish: An Autobiography. By Peter Medawar. Oxford University Press:1986. Pp.209. £12.50, \$17.95.

WITH the honesty and irreverence that have long been his trademarks, Peter Medawar begins his autobiography with three quotations, one his own, explaining why the lives of scientists make such dreadful reading. Choosing his own version from Pluto's Republic:

The lives of scientists, considered as Lives, almost always make dull reading... . It could hardly be otherwise. Academics can only seldom lead lives that are spacious or exciting in a worldly sense... . Their work is in no way made deeper or more cogent by privation, distress, or worldly buffetings... . Academics lie outside the devastation area of the literary convention according to which the lives of artists and men of letters are intrinsically interesting, a source of cultural insight in themselves. If a scientist were to cut his ear off, no one would take it as evidence of a heightened sensibility.

Medawar's brave attempt in the light of his own strictures does, as he would readily admit, encounter these intrinsic problems of the genre. His life, as he describes it, has the continual interior excitement that is God's greatest gift to productive intellectuals, but not the exterior oomph that provides the stuff of good cinema. Moreover, where he has learned or experienced (as we all have) private items of greater import or taller tales, he has the unfailing decency to maintain both the trust and privacy of these knowledges. The central problem of autobiography is not confined to scientists: no person of integrity can possibly write with full disclosure, particularly for what we know of others (no matter how open we choose to be about ourselves).

Thus, one might say, at a superficial reading, that Medawar is hoist by his own petard. (I confess that I haven't the slightest idea what a petard is, but the phrase has such a nice ring. Update: I just looked it up - I always supposed it was a kind of tie; but it's an instrument of war, an explosive battering ram.) So hoist he is, but for one transcendent matter: Peter Medawar is so fine a writer (the world's best among scientists), so full of wisdom and insight, that he has been able to compose the very best example of what may be, by his own admission, a deeply flawed genre.

His Memoir of a Thinking Radish proceeds conventionally. (His odd, quintessentially Medawarian title, is a deliciously oxymoronic cut-and-paste job of Falstaff's and Pascal's epitomes for the human condition.) We learn of his misery tempered with good humour as a lonely boy at snobby public school (prep for American readers), where well-bred boys did not take ease". guru of our age). kindly to one "of Arabic extraction" (Medawar's father was Lebanese, his mother English; he quotes a friend of similar "extraction" who said: "I can't bear that expression, it makes you sound like some kind of gum".) In this section on his early life, Medawar first gives vent to a central theme of this book (so identified in his introduction): that Britain's greatness has been sapped not by loss of empire or

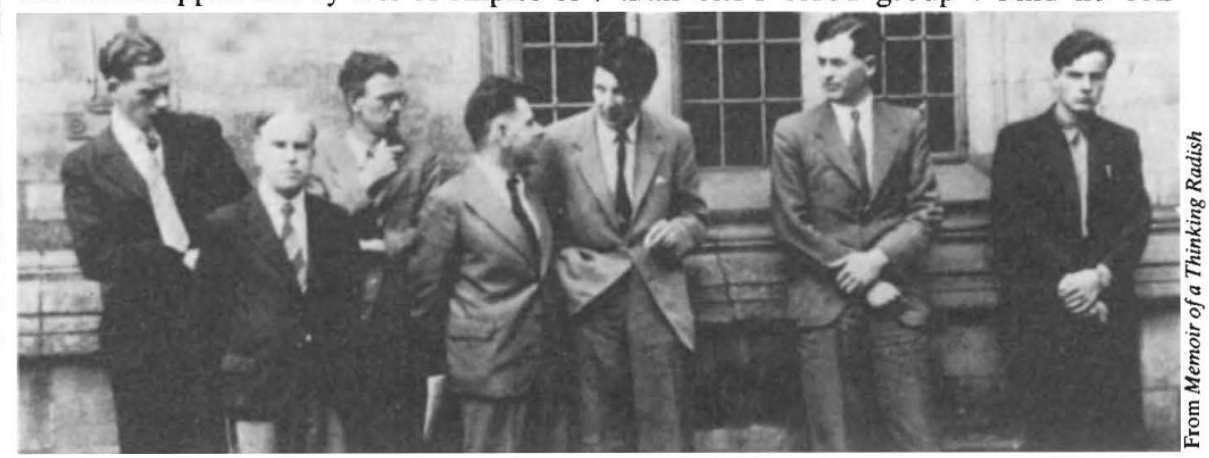

Three generations of Oxford teachers - members of the Theoretical Biology Club at Magdalen College in 1946. (From left to right) Francis Huxley, J.H. Woodger, Hans Motz, Karl Popper, J.Z. Young, Peter Medawar and Avrion Mitchison.

other worldly things, but by the internal intolerance and petty narrow-mindedness of its ruling élites, a condition that he calls "snobismus", or simply "the English dis-

We then follow Medawar's career from Oxford, where he showed brilliance and general commitment to matters intellectual, but only found his specific path within science by probing, and trial and error; to years of fruitful research and stewardship of several academic and medical institutes (I had known of Medawar's seminal contributions to biological thinking, but not of his skills at, indeed strong fondness for, tasks of administration that I would find onerous or soul-destroying, but that he managed to invest with creativity); to his current life, after a serious stroke made bench-top laboratory work impossible, as a writer and director of research (and, in my view, as the biological

I particularly appreciated his candid descriptions and thoughtful generalizations about his primary work in immunology, especially his discovery of acquired immunological tolerance (the practical basis for techniques of grafting and transplant that have saved and extended so many human lives), and for which he and Macfarlane Burnet shared the Nobel Prize for Medicine and Physiology in 1960. Medawar emphasizes that the importance of these studies lay not so much in the specifics (for much of the work has been super- seded both conceptually and practically), but in breaking an ideological lock that had subtly led scientists to a belief that such things could not be done. Many predecessors had not tackled the subject of organ and tissue transplantation because a prevailing view of genetic inexorability (stronger in more class-conscious Britain than elsewhere) had implied that a person's intrinsic construction could not be so compromised by accepting foreign bits into a working machinery. Medawar writes: "Some people had maintained that this was in principle impossible, since substances that provoke the normal rejection reaction are part of the genetic make-up, something that could no more be changed than one's blood group". And he con-

cludes, "the ultimate importance of the discovery of tolerance turned out to be not practical, but moral. It put new heart into the many biologists and surgeons who were working to make it possible to graft, for example, kidneys from one person to another".

Medawar has managed to transcend the limitations of autobiography by lacing his ordinary and largely anecdotal account with three saving graces.

First, he has provided practical examples from his career to illustrate the important themes that he has emphasized in his famous essays (see Pluto's Republic, The Uniqueness of the Individual, Advice to a Young Scientist). Medawar has shown, in these essays, how the conventional style of scientific writing misconstrues, even falsifies, the actual doing of science - a vital point for public communication since it is ce, much more than its content, that nonscientists so desperately misunderstand. The epitomized logic of inductivist accounts - from introduction, to materials and methods, results and conclusions - omits the basic human dimensions of hypothesis, confusion, error and collegiality. The false starts are in the wastebasket, not the Science Citation Index. By focusing his text on the frustrations, the errors and the bullheaded approaches, until kicked in the pants by data or good advice from colleagues with other perspectives, Medawar has illustrated his favourite the procedures and methodology of scien- 
themes by honestly discussing his own work.

Second, no one can match Medawar for verbal wit and dexterity; the bon mot on every second page compensates for any uninspired conventionality elsewhere. Where else can we learn so well about the dangers of Bible-reading for young children, the insipidity of American football or problems of defecation in a public school that instilled fortitude (and probably thought it inhibited homosexuality) by refusing to install doors in the lavatories: "This circumstance so offended the

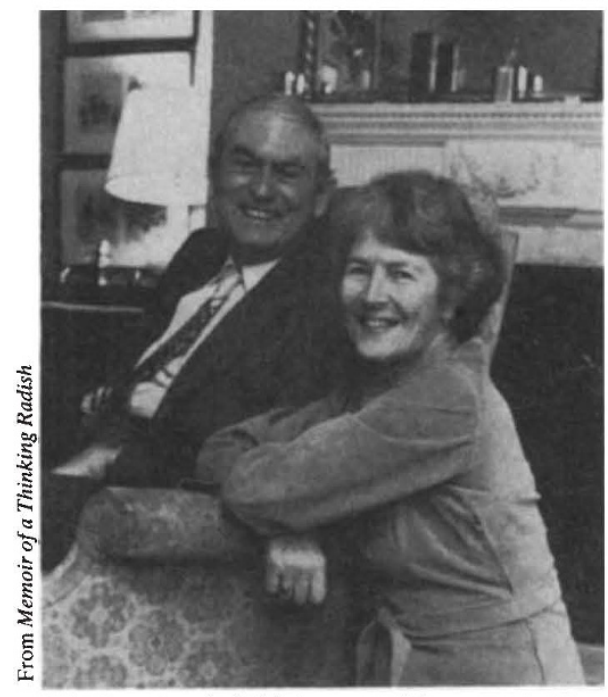

"Entire visual field is agreeably occupied" Peter Medawar with his wife Jean in 1980.

Poet Laureate-to-be, John Betjeman, a Marlborough boy, that in his poem Summoned by Bells he implies that he had no bowel movement for three years".

Third, we find behind the witticisms, so well (and movingly) illustrated because implied rather than announced, that most rare and precious trait of courage, expressed, as an intellectual must, in word as well as deed. For more than a decade, Peter Medawar has worked, as productively as ever in his life, if not more so, under conditions of physical disadvantage (a major stroke and several aftermaths) that would have led most people to despair and resignation. Consider only his first words to his wife Jean, upon seeing her face after waking up from an operation (and fearing that a right-sided cerebral haemorrhage had destroyed vision in the left half of each eye): "My first words were 'Entire visual field is agreeably occupied.' I thought this remark apposite and well turned and it repudiated the case that my mind had deteriorated beyond hope of recovery".

The scientific autobiography is an irretrievably flawed literary genre, but when practised by the premier, the nonpareil, the numero uno, the top banana of the profession, it can be pretty darned good. $\square$

Stephen Jay Gould is a Professor in the Museum of Comparative Zoology, Harvard University, Cambridge, Massachusetts 02138, USA.

\section{Resonance through the editions}

\section{John Maddox}

A New Science of Life: The Hypothesis of Formative Causation (A New Edition). By Rupert Sheldrake. Anthony Blond, London: 1985. Pp. 278. Pbk £8.95.

THOSE who review books are often faced with the task of dealing with books without merit; wise review editors advise that the appropriate treatment for them is no treatment at all, for even a scornful review of a second-rate work may seem like an advertisement for it. But what should be done about books that are worse than that, those that are perverse? Such documents are often designed to captivate opinion, and there is a case for denouncing them. But one should tread carefully. That, at least, is this journal's experience with Dr Rupert Sheldrake's book $A$ New Science of Life, first published in 1981 and discussed in a leading article on 24 September of that year (Nature 293, 245; 1981) under the title "A book for burning?". What has happened now is that Sheldrake's book has been reissued in what is called a new edition, which differs most noticeably from the first in its bulky appendix filled with self-congratulatory references to the "controversy" following its first appearance.

Sheldrake, it may be recalled, is a biochemist turned metaphysicist who is the originator of the "hypothesis of formative causation", the assertion that the shapes of things, animate or inanimate, are determined by what are called "morphogenetic fields", by a process called "morphogenetic resonance". What seems to puzzle Sheldrake is that a journal such as this should be convinced that his book is a mischievous aberration. Here is an explanation, a routine argument so valuable in, for example, the return to their authors of manuscripts showing that special relativity is a pack of lies, or that quantum mechanics is mistaken, that it might be set up on a word processor for the more efficient conduct of editorial business.

The fact that there are unsolved problems within the framework of an existing theory does not of itself imply that the theory must be thrown away, or replaced by another; unsolved problems are the essence of science, the means by which theories are refined. Three centuries of physical science attest to that. In biology, the conventional theoretical framework is much younger; many would say that even Darwin's evolution became usable only in the 1920 s, while molecular biology is just over 30 years old. Yet the Sheldrakes wring their hands about the puzzle that the difference between the genomes of differ- ent species of Drosophila may be greater than that between the genome of human beings and the chimpanzee, shake their heads in disbelief at the prospect that the process of differentiation will ever be understood, assert (accurately, no doubt, but pointlessly) that there is no prospect of a "mechanistic" explanation of parapsychology - and plump instead for a theory which can account for everything, but at the cost of explaining nothing. So long as these morphogenetic fields have not been measured or otherwise described, their all-pervasive utility in the communication of form is merely a way of making accidents so generally reproducible that they become the rule.

This is elementary textbook stuff. Sheldrake's thesis as it stands is merely a simulacrum of a theory in the sense of an explanation, but for which Sheldrake claims support from Thomas Kuhn's innocent observation (in his valuable book On Scientific Revolutions) that people tend to resist the overthrowing of old "paradigms". Sheldrake takes this to be a licence for discarding any paradigm that comes to hand. His advocacy of his thesis is mischievous because it is overtly designed to give aid to that great company of people who think that the paranormal is the normal, that parapsychology is a more urgent problem for orthodox science than, say, that of differentiation in biology, and that Jung's collective unconscious is a fact of life.

Readers of this new edition will nevertheless observe that the past four years have not been conspicuously successful for formative causation. People have offered prizes for tests of the hypothesis, but the experiments seem to have been confined, for the time being, to the activities of television programmes. (A West German channel is said to be about to follow two British channels with a test of whether some people's knowledge of the hidden image in a puzzle picture will make it easier for others to tell the answer.) Lamely, the long appendix ends with the promise that "... other experiments ... are in progress in different parts of the world; and some of their results will probably be published within the next year or two".

The moral, for book reviewers, should by now be plain. Not all bad books should be censured, only those whose influence is so compelling, and so pernicious, that they must be resisted. Sheldrake's, which from the outset contained the ingredients of its own implausibility, should have been ignored. As things have turned out, the spurious controversy stirred in the appendix to this new edition gives the issue an air of durability it would otherwise have lacked. Presumably the appendix to the next edition will reprint this article, and so on....

John Maddox is Editor of Nature. 